\title{
Duration of Preoperative Scrotal Pain May Predict the Success of Microsurgical Varicocelectomy
}

\author{
Bulent Altunoluk, Haluk Soylemez, Erkan Efe, Onder Malkoc \\ Department of Urology (BA, EE, OM), Faculty of Medicine, Sutcu Imam University, Kahramanmaras, \\ Turkey and Department of Urology (HS), Izmir Military Hospital, Izmir, Turkey
}

\begin{abstract}
Purpose: Varicocelectomy is used in the treatment of scrotal pain. We report our results with microsurgical subinguinal varicocele ligation to treat pain.

Materials and Methods: A total of 284 men underwent subinguinal microsurgical varicocele ligation for scrotal pain. All patients were asked to return for a follow-up evaluation 3 months after surgery, which included a physical examination, as well as questions on pain severity, number of days required before their return to work and development of any postoperative complications.

Results: Median patient age at the time of varicocele ligation was 23.7 years (range 16-38 years). The average duration of pain before presentation was 11.2 months (range 1 month to 40 months). In $85.6 \%$ patients there was complete resolution of pain and $6.3 \%$ had partial resolution. Pain persisted postoperatively in 19 cases $(8.1 \%)$. There were statistically nonsignificant differences in the characteristics of the pain and grade of varicocele between postoperative groups. A significant difference was observed in postoperative success between patients who had long period and those who had short period of pain.

Conclusions: Sub-inguinal microsurgical varicocele ligation is an effective treatment for painful varicocele. The duration of pain preoperatively may predict outcomes in selected patients.
\end{abstract}

Key words: testis; varicocele; pain; microsurgery; outcome assessment

Int Braz J Urol. 2010; 36: 55-9

\section{INTRODUCTION}

The estimated incidence of varicoceles is approximately $15 \%$ in the male population and $37 \%$ in subfertile men (1). It is a cause of pain in $2 \%$ to $14 \%$ of men suffering chronic scrotal pain $(2,3)$. The most common complaint is dull aching pain which becomes worse after exercise. Traditional indications for varicocele treatment are infertility and pain. Several techniques have been used for the surgical ligation of varicocele such as high, inguinal, subinguinal, scrotal, microscopic and laparoscopic ligation (4-6).
Treatment of a painful varicocele traditionally consists of conservative management, followed by surgery if unsuccessful. This study attempted to examine the success rate of varicocele ligation when performed for the treatment of pain and to evaluate the affect of the duration of pain.

\section{MATERIALS AND METHODS}

A total of 284 men with a median age of 23.7 years (range 16-38) underwent microsurgical varico- 
cele ligation for painful varicocele from 2005 to 2008 . Ethics Committee approval and informed consent was obtained from all patients. The diagnosis of varicocele was based on the findings from both physical examination and color Doppler ultrasound. Patients who had other causes of scrotal pain, such as testicular torsion, epididymitis, inguinal hernia, testicular tumor or trauma, were excluded from the study. Varicocele was graded according to the criteria defined by Lyon and colleagues: Grade I as palpable only with Valsalva maneuver, Grade II as palpable without Valsalva and Grade III as visible from a distance (7). Patients described pain with testicular discomfort as a dull ache or scrotal heaviness, especially after standing long time. All the patients underwent a preoperative trial of conservative management for pain (nonsteroidal antiinflammatory medication, scrotal elevation and limitations in activity) approximately 1 month. None of the patients had any benefit from conservative treatment. According to the duration of pain before surgery the patients were divided into two groups. The first group consisted of 141 patients whose pain was longer than 3 months. The second group was composed of 96 patients who had a short duration of pain, less than 3 months.

Microsurgical subinguinal varicocelectomy was performed in all patients (3) with an operating microscope under general or spinal anesthesia and were hospitalized for 12 to 24 hours. Varicocelectomy was performed through a small transverse skin incision overlying the external inguinal ring. The incision was extended through Camper's and Scarpa's fascias, allowing for the spermatic cord to be grasped with a Babcock clamp. The spermatic cord and testicle were then delivered through the incision. The gubernacular veins and external spermatic perforators were isolated and divided. The testicle was placed back into the scrotum, the microscope was then brought into the operating field, and the cord was examined under 8- to 15-power magnification. Once the internal and external spermatic fascias were incised, the underlying testicular artery or arteries were identified by their subtle pulsations. The artery was then dissected free from the underlying veins and encircled with a 2-0 silk ligature, for identification. Care was taken to preserve lymphatics to prevent the development of a hydrocele. All internal spermatic veins with the exception of the vasal veins were then ligated with 4-0 silk and divided.
At the end of the procedure, the cord was skeletonized so that it only contained the spermatic artery(s), lymphatics, and the vas deferens and its accompanying veins and $\operatorname{artery}(\mathrm{s})(8,9)$.

All patients were asked to return for a followup visit 3 months after surgery. Follow-up evaluation included physical examination, questioning pain severity (compared with preoperative pain severity), number of days required to return to work and development of any postoperative complications. After surgery patient response was graded as a complete response (pain was completely absent after surgery), partial response (pain persists but was reduced after surgery) and no response (pain remained unchanged after surgery) (10). Preoperative state and postoperative outcome of patients was compared by using a chi-squared test. $\mathrm{P}<0.05$ was considered statistically significant. SPSS v 15.0 software program was used for statistical analysis.

\section{RESULTS}

The median patient age at the time of varicocele ligation was 23.7 years (range $16-38$ years). The varicocele was present on the left side in 202 patients $(85 \%)$ and bilateral in $35(15 \%)$. Varicocele was grade III in $161(67.9 \%)$ patients, grade II in $67(28.3 \%)$ and grade I in $9(3.8 \%)$.

Patients described pain with testicular discomfort as a heaviness or dull ache, generally after standing all day. The median duration of pain before presentation was 11.2 months (range 1 month to 40 months).

Of these 284 men, 237 (83.4\%) were available for follow-up 3 months postoperatively.

Of the 237 patients with a follow-up visit at 3 months postoperatively, 203 patients $(85.6 \%)$ reported complete resolution of their pain, and 15 (6.3\%) reported partial resolution. Thus, varicocele ligation was successful in $218(91.9 \%)$ patients. 19 patients $(8.1 \%)$ reported no change from their preoperative condition.

There were neither intraoperative nor postoperative complications. The total number of days required to return to work ranged from 5 to 23 days (mean 9.3 days). 
Recurrence was detected in one of 19 patients who had postoperative scrotal pain and 17 of these patients had pain duration shorter than 3 months at presentation.

While the success rate of the patients with long period of pain was 139/141 (98.6\%), the patients who had short duration of pain had a success rate of 79/96 (82.3\%), Table-1.

\section{COMMENTS}

Varicocele ligation for the treatment of pain is only recommended where conservative management has failed and in a highly selected population of men who have specific pain complaints. Several studies have been published examining the effectiveness of varicocele ligation in the treatment of scrotal pain. Surgical approaches include high, inguinal, subinguinal, scrotal, laparoscopic, and microscopic ligation. The microscopic techniques are associated with the least number of complications and the lowest recurrence rates (11). Therefore, we used a microdissection technique through a subinguinal approach in all patients. Peterson et al. (12) and Yaman et al. (13) reported complete resolution of pain in 86 and $88 \%$ of patients, respectively. Yeniyol et al. (14) showed that high ligation of varicocele is effective to treat pain with similar results $(82.8 \%)$ compared to the other studies. Karademir et al. (15) showed similar results (83.4\%) using inguinal and subinguinal ligation and suggested that surgical technique may influence outcomes. Compared to the other studies reported in the literature our success rate $(85.6 \%)$ had a compatible level.
Yaman et al. (13) suggested that the failure rate was associated with the preoperative varicocele grade. We found no association between varicocele grade and pain resolution after surgery. Yaman et al. (13) examined recurrence using color Doppler ultrasound in the failure group and they found reflux recurrence in two of the nine patients. In our study, recurrence was found in 1 of the nineteen patients who had persistent or worse pain following surgery. We did not detect any recurrent reflux among the other patients with treatment failure. This result would suggest that persistence of the pain was probably not related to varicocele recurrence.

Underlying pathology other than varicocele, such as idiopathic orchialgia, epididymitis, or a surgical complication (e.g., hydrocele) might be the cause of treatment failure after non microsurgical varicocelectomy (8).

Buheissi et al. (16) reported a success rate of $76.5 \%$ in their study. These authors stated that patients presenting with dull pain had a significant success in the resolution of pain than patients with sharp pain. It is thought that postoperative success rate is associated with pain characteristics.

Another important point of treatment of painful varicocele is defining the character of the pain. As described by Peterson et al. (12) the pain must be dull, aching and throbbing without components of sharp or radiating pain. All our patients' complaints fully matched these pain criteria.

There were no statistically significant differences in either the quality and intensity of pain or varicocele grade between postoperative outcomes in the failure group. Only the duration of pain seems to be the factor that is considerably associated with pain

Table 1 - Results of varicocelectomy according to duration of pain.

\begin{tabular}{lccc}
\hline Duration of Pain & \multicolumn{2}{c}{ Varicocelectomy } & Total \\
& Success & Failure & \\
\hline$>3$ months & 139 & 2 & 141 \\
$(\mathrm{~N}=141)$ & $(98.6 \%)$ & $(1.4 \%)$ & $(100 \%)$ \\
& & & 96 \\
$(\mathrm{~N}=96)$ & 79 & 17 & $(100 \%)$ \\
\hline
\end{tabular}


resolution. Patients who presented with long time (> 3 months) pain had a significantly higher chance of benefiting from the operation compared to patients who presented with short time pain $(\mathrm{p}<0.05)$.

Duration of pain before surgery could be a factor used to predict success where patients presenting with long-lasting pain had a significant success in the resolution of pain. On the other hand, patients presenting with short period of pain significantly failed to benefit from the varicocele ligation.

\section{CONCLUSIONS}

Microsurgical subinguinal varicocele ligation for scrotal pain is successful when performed in selected patients who have specific complaints. The duration of pain before surgery may be a factor which could affect the success. The low rate of complications and recurrence of microsurgical varicocelectomy is essential, since complications and recurrence could be indicated by pain persistence. A prospective randomized study with long follow-up period and large population is required to support the present data.

\section{CONFLICT OF INTEREST}

None declared.

\section{REFERENCES}

1. Meacham RB, Townsend RR, Rademacher D, Drose JA: The incidence of varicoceles in the general population when evaluated by physical examination, gray scale sonography and color Doppler sonography. J Urol. 1994; 151: 1535-8.

2. Kass EJ, Marcol B: Results of varicocele surgery in adolescents: a comparison of techniques. J Urol. 1992; 148: 694-6.

3. Marmar JL, Kim Y: Subinguinal microsurgical varicocelectomy: a technical critique and statistical analysis of semen and pregnancy data. J Urol. 1994; 152: 1127-32.

4. Palomo A: Radical cure of varicocele by a new technique; preliminary report. J Urol. 1949; 61: 604-7.

5. Ivanissevich O: Left varicocele due to reflux; experience with 4,470 operative cases in forty-two years. J Int Coll Surg. 1960; 34: 742-55.
6. Nyirády P, Kiss A, Pirót L, Sárközy S, Bognár Z, Csontai A, et al.: Evaluation of 100 laparoscopic varicocele operations with preservation of testicular artery and ligation of collateral vein in children and adolescents. Eur Urol. 2002; 42: 594-7.

7. Lyon RP, Marshall S, Scott MP: Varicocele in childhood and adolescence: implication in adulthood infertility? Urology. 1982; 19: 641-4.

8. Chawla A, Kulkarni G, Kamal K, Zini A: Microsurgical varicocelectomy for recurrent or persistent varicoceles associated with orchalgia. Urology. 2005; 66: 1072-4.

9. Esteves SC, Glina S: Recovery of spermatogenesis after microsurgical subinguinal varicocele repair in azoospermic men based on testicular histology. Int Braz J Urol. 2005; 31: 541-8.

10. Levine LA, Matkov TG, Lubenow TR: Microsurgical denervation of the spermatic cord: a surgical alternative in the treatment of chronic orchialgia. J Urol. 1996; 155: 1005-7.

11. Goldstein M, Gilbert BR, Dicker AP, Dwosh J, Gnecco $\mathrm{C}$ : Microsurgical inguinal varicocelectomy with delivery of the testis: an artery and lymphatic sparing technique. J Urol. 1992; 148: 1808-11.

12. Peterson AC, Lance RS, Ruiz HE: Outcomes of varicocele ligation done for pain. J Urol. 1998; 159: 1565-7.

13. Yaman O, Ozdiler E, Anafarta K, Gögüs O: Effect of microsurgical subinguinal varicocele ligation to treat pain. Urology. 2000; 55: 107-8.

14. Yeniyol CO, Tuna A, Yener H, Zeyrek N, Tilki A: High ligation to treat pain in varicocele. Int Urol Nephrol. 2003; 35: 65-8.

15. Karademir K, Senkul T, Baykal K, Ates F, Iseri C, Erden D: Evaluation of the role of varicocelectomy including external spermatic vein ligation in patients with scrotal pain. Int J Urol. 2005; 12: 484-8.

16. Al-Buheissi SZ, Patel HR, Wazait HD, Miller RA, Nathan S: Predictors of success in surgical ligation of painful varicocele. Urol Int. 2007; 79: 33-6.

Accepted after revision:

July 27, 2009

\section{Correspondence address:}

Dr. Bülent Altunoluk

Assistant Professor

Department of Urology

Faculty of Medicine, Sutcu Imam University

Kahramanmaras, Turkey

Fax: + 90344 221-2371

E-mail:drbulenta@yahoo.com 


\section{EDITORIAL COMMENT}

Scrotal pain is often a diagnostic and therapeutic challenge. This work confirms the results already reported in literature $(1,2)$ about the beneficial effects of surgical treatment for a large number of patients suffering from varicoceles and scrotal pain.

Microsurgical technique permits better preservation of anatomical structures and this leads to a very low number of complications (3-5). The data about persistent discomfort after long preoperative scrotal pain show that this information could be useful to treat painful varicocele a short time after diagnosis.

This technique could therefore be one of the best options to treat painful varicoceles.

\section{REFERENCES}

1. Mohammed A, Chinegwundoh F: Testicular varicocele: an overview. Urol Int. 2009; 82: 373-9.
2. Yaman O, Soygur T, Zumrutbas AE, Resorlu B: Results of microsurgical subinguinal varicocelectomy in children and adolescents. Urology. 2006; 68: 410-2.

3. Cayan S, Shavakhabov S, Kadioðlu A: Treatment of palpable varicocele in infertile men: a meta-analysis to define the best technique. J Androl. 2009; 30: 33-40.

4. Schiff J, Kelly C, Goldstein M, Schlegel P, Poppas D: Managing varicoceles in children: results with microsurgical varicocelectomy. BJU Int. 2005; 95: 399-402. Erratum in: BJU Int. 2005; 96: 710.

5. Al-Said S, Al-Naimi A, Al-Ansari A, Younis N, Shamsodini A, A-sadiq K, Shokeir AA: Varicocelectomy for male infertility: a comparative study of open, laparoscopic and microsurgical approaches. J Urol. 2008; 180: 266-70.

Dr. Luca Carmignani \& Dr. Luca Lunelli Clinica Urologica I Università degli Studi di Milano Milan, Italy E-mail: luca.carmignani@unimi.it 